Signs of selfishness - the effect of the meiotic drive gene Segregation Distorter $(S D)$ in the fruitfly Drosophila. Both of these electron micrographs show a section through the head region of a sperm bundle $(x \sim 7,500)$. Normally (left) the nuclei in a bundle of 64 developing sperm cells form 64 sperm heads. In flies carrying $S D$ (right) only

32 heads mature, those that will pass on the SD gene. (Reproduced from Scientific American February 1979. Micrographs by R. W. Hardy and K. T. Tokuyasu.)

instance, are hosts to bacteria that are exclusively maternally inherited. Because of this transmission pattern, these factors have no evolutionary interest in being in sons and many manipulate their host in one way or another to prevent this from occurring. In certain wasps ${ }^{7}$, for example, there are bacteria that force their female host to reproduce asexually and have exclusively female offspring. This phenomenon has evolved at least five times ${ }^{8}$. In Crustacea some bacterial symbionts have evolved to turn sons into daughters ${ }^{9}$, while in numerous insects there are symbionts that kill sons ${ }^{10}$.

The induction of parthenogenesis in wasps and feminization in crustaceans is performed by the same 'species' of intracellular symbionts (Wolbachia pipientis). In other species this bacterium induces 'cytoplasmic incompatibility'. Here the bacteria stay in the male but somehow poison the sperm so that progeny sired with uninfected females die (infected eggs develop normally).

Jack Werren and colleagues ${ }^{3}$ have surveyed 154 species of neotropical insects for Wolbachia. Rather than looking for the phenotypic footprint of the selfish element, they used the polymerase chain reaction and dot blot to detect the version of the $f t s Z$ gene specific to Wolbachia. They found it in 16.9 per cent of species, and in a similar percentage of insects in the United States, and by extrapolation calculate that, overall, between 1.69 and 5.07 million species of insect are infected. Later studies have reported Wolbachia in both mites ${ }^{11}$ and a filarial worm ${ }^{12}$. It is not known what proportion of Wolbachia infections exhibit or exhibited selfish effects. But given that cytoplasmic incompatibility can potentially induce reproductive isolation between populations, it is reasonable to speculate ${ }^{3}$ that the spread of Wolbachia could be a major cause of speciation.

It is tempting to assert from such findings that selfish elements are common, but often unnoticed. Such a conclusion, however, is wrong, for not all well studied species have selfish elements that have major effects. There are probably good reasons for this, one being that the spread of selfish elements often requires the species to be outbreeding. It is probably for this reason that yeast, Caenorhabditis and Arabidopsis harbour only relatively small-effect selfish factors (transposons, for example). The other common laboratory species, drosophilids and mice, are all naturally outbred and commonly have major-effect selfish factors ${ }^{4}$.

The outbreeding rate is not, however, the sole determinant of the distribution of selfish elements. Male-killing elements die when the male dies. For this to be a successful strategy some advantage must be given to the dead males' sisters. This requirement limits the distribution of such factors but also explains why they are prevalent in species with intra-brood cannibalism and gregarious clutches ${ }^{10}$. In ladybirds, in which conditions seem near perfect for male-killers, work in our department showed that three out of seven randomly chosen species had the factors. In one species male-killing has evolved at least twice.

There remains one curious species that is both well studied and outbred, but shows very little evidence of harbouring major-effect selfish elements. Although there are descriptions of curious sex ratios $^{13}$ and, occasionally, of weak segregation distortion (for example see ref. 14), there are no convincing reports of such a selfish element in humans.

Laurence D. Hurst and Gregory D. D. Hurst are in the Department of Genetics, University of Cambridge, Downing Street, Cambridge CB2 3EH, UK.

1. Jaenike, J. Am. Nat. 148, 237-254 (1996).

2. Merçot, H. et al. J. Evol. Biol. 8, 283-300 (1995).

3. Werren J. H. Windsor, D. \& Guo, L. R. Proc. R. Soc. Lond. B 262, 197-204 (1995).

4. Hurst, L. D., Atlan, A. \& Bengtsson, B. O. Q. Rev. Biol 71, 317-364 (1996)

5. Hurst, L. D. Genetics 142, 641-643 (1996).

6. Taylor, D. R. Heredity 74, 518-526 (1994).

7. Stouthamer, R. \& Kazmer, D. J. Heredity 73, 317-327 (1994).

8. Werren, J. H., Zhang, W. \& Guo, L. R. Proc. R. Soc. Lond. B 261, 55-63 (1995).

9. Legrand, J. J., Legrand-Hamelin, E. \& Juchault, P. Biol. Rev. 62, 439-470 (1987)

10. Hurst, G. D. D. \& Majerus, M. E. N. Heredity 71, 81-95 (1993).

11. Breeuwer, J. A. J. \& Jacobs, G. Exp. Appl. Acar. 20 421-434 (1996).

12. Sironi, M. et al. Mol. Biochem. Parasitol. 74, 223-227 (1995)

13. Leinhart, R. \& Vermelin, H. C.R. Soc. Biol. Paris $\mathbf{1 4 0}$ $537-540$ (1946).

14. Evans, K. et al. Nature Genet. 6, 210-213 (1994).

\section{Second sight}

ALDous Huxley, the great prophet of hallucinogenic drugs, had very bad eyesight. He was entranced by chemically induced visions - they were the first sharply focused things he had ever seen. Daedalus is now building on his experience.

The eye is much more than a mere camera. The retina, and its optical pathways to the brain, actively process and interpret what they see. There are specific cells which react to edges of various orientations, to movements in different directions, to differences between signals from the two eyes, to specific spatial frequencies. Farther back in the system, individual objects are recognized and identified. The hallucinogens, says Daedalus, must sabotage this delicate machinery by binding selectively to specific cells. In low doses they can merely enhance colours or shapes. Other drugs seem to target different cells. Some carbamates blur the vision; strychnine in tiny doses sharpens perception; a rare side-effect of ranitidine is to abolish colour vision.

DREADCO biochemists are expanding these observations. They are seeking drugs which, so to speak, will conduct by software the operations now performed in hardware by ophthalmic lenses. A drug which damped down the cells handling low spatial frequencies, or excited those handling high spatial frequencies, would sharpen the vision. One which acted preferentially on the cells detecting specific angles could equalize the biased angular contrast of astigmatism. One which targeted the cells of binocular fusion could merge the images from divergent eyes. Daedalus hopes to perfect a range of 'pharmacological spectacles': drugs to be made up by the optician according to the defects revealed by his eye-test. A simple course of tablets will then give perfect sight, ending the long tyranny of frames and contact lenses.

But Daedalus goes further. $\mathrm{He}$ is seeking compounds to affect the deeper visual interpretations. A stimulant for the motion-sensing cells would do wonders for the skills of driving, machining and similar dynamic tasks. Conversely, one which extended the persistence of vision would allow the user to appreciate jerky old films, or see a sequence of slides as a moving picture. A drug which emphasized the differences between straight, curved and closed letters would please proof-readers and dyslexics. A pill which clarified the key differences between human faces would lay to rest many social anxieties, while pills which heightened perception of mislaid keys, or parking spaces, or policemen, would all find market niches.

David Jones 